\title{
PRINCÍPIO DA RESPONSABILIDADE OBJETIVA VIGENTE NAS NORMAS ANTIDOPING E OS DIREITOS HUMANOS DOS ATLETAS: UMA ABORDAGEM CRÍTICA
}

\author{
THE STRICT LIABILITY PRINCIPLE IN ANTIDOPING RULES \\ AND THE HUMAN RIGHTS OF ATHLETES: AN APPROACH CRITICAL
}

\author{
AUTORES \\ Renata da Cruz Cunha ${ }^{1}$ \\ Rodolfo de Alkmim Moreira Nunes ${ }^{1}$ \\ Giovanni da Silva Novaes ${ }^{2}$ \\ Maria Irany Knackfuss \\ Hênio Ferreira de Miranda' \\ Francisco Ivo Dantas Cavalcanti ${ }^{1}$ \\ ${ }^{1}$ Universidade Federal do Rio Grande \\ do Norte, Brasil \\ ${ }^{2}$ Universidade de Trás os Montes e Alto Douro
}

PRINCÍPIO DA RESPONSABILIDADE OBJETIVA VIGENTE NAS NORMAS ANTIDOPING E OS DIREITOS HUMANOS DOS ATLETAS: UMA ABORDAGEM CRITICA 4(1): 83-87

\section{PALAVRAS-CHAVE}

doping; responsabilidade objetiva; direitos humanos.

\section{KEYWORDS}

doping; strict liability;

human rights.

data de submissão

Setembro 2007

data de aceitação

Dezembro 2007

\section{RESUMO}

Fundamentação: o ser humano vive em busca de superação em todos os níveis, seja profissional, emocional ou em suas relações interpessoais. No meio esportivo essa busca se torna mais visivel, pois centésimos de segundos podem fazer a diferença entre o pódio e o fracasso. A mídia a todo instante anuncia um novo caso de doping positivo nas mais variadas modalidades esportivas. Objetivo: verificação dos processos julgados pelo Superior Tribunal de Justiça Desportiva - STJD do Atletismo brasileiro entre os anos de 2003 e 2006, a luz da Declaração Universal dos Direitos Humanos, dos princípios constitucionais constantes na carta magna brasileira de 1988 e o princípio do inquisitório, ou da common law presente nos processos perante a justiça desportiva e pregados pela Agencia Internacional de Combate ao Doping (WADA]. Materiais e Métodos: foram analisados 18 processos pelo uso de substância proibida, entre os anos de 2003 a 2006 junto a Justiça Desportiva do Atletismo, de atletas do sexo masculino e feminino. Resultados: dos 18 processos analisados somente 3 foram absolvidos pelo STJD, no entanto, destes 3 , dois cumpriram suspensão por dois anos, tendo em vista que WADA, não satisfeita com os resultados, solicitou que a Federação Internacional (IAAF) fizesse uma análise dos casos, encaminhando-os a Corte Arbitral do Esporte [CAS]. Conclusão: a regra da responsabilidade objetiva confronta com nossos princípios constitucionais e com a declaração universal dos direitos hu- manos, levando atletas a responderem por ato ilícito para o qual não restou devidamente comprovada sua culpa.

ABSTRACT

Back Ground: the human lives in search of overrun at all levels, whether professional, emotional or in their interpersonal relationships. In the middle of sports this search becomes more visible, because hundredths of seconds can make the difference between the podium and the failure. Journals at any moment announces a new case of a positive doping in several sports. Objective: analyse the processes judged for doping in the STJD of the Brazilian athletism and verify if the pronounced sentences are in accordance with the Brazilian Constitution and with the Universal Declaration of the Human Rights. Materials and Methods: 18 cases were reviewed by the use of prohibited substance, between the years 2003 to 2006 by the STJD of Athletism. Results: of the 18 cases examined only 3 were acquitted by the STJD, however, these three, two have met suspension for two years, in order that WADA, not satisfied with the results asked the International Federation (IAAF) to analyze them, and after guided them to the Court of Arbitration Sports [CAS]. Conclusion: the rule of objective responsibility are not in accordance with the Brazilian Constitution and with the Universal Declaration of the Human Rights, leading athletes to respond irrespective proven their guilt. 


\section{INTRODUĈ̣̃O}

0 Atletismo é chamado de esporte-base, porque para sua prática são realizados movimentos naturais do ser humano, como: correr, saltar, lançar. Hoje, este é definido como um esporte com provas de pista (corridas), de campo [saltos e lancamentos), provas combinadas, como decatlo e heptatlo (que reúnem provas de pista e de campo], o pedestrianismo (corridas de rua, como a maratona), corridas em campo (cross country), corridas em montanha, e marcha atlética.

Nos esportes de alto rendimento, principalmente nos individuais, a busca por soluções milagrosas que levem a melhora da performance, muitas vezes leva o atleta ao uso de substâncias proibidas ${ }^{1}$. A este uso chamamos de doping ou dopagem. Para a Agência Mundial de Combate ao Doping (WADA) criada no ano de 1999 e ligada ao Comitê Olímpico Internacional (COl) define-se doping ou dopagem como a Verificação, de uma ou mais violações das normas antidopagem indicadas nos artigos 2.1 a 2.8 do Código Mundial Anti-Doping (CDMA)., ${ }^{9,15}$

Este código, adotado por grande parte das federações internacionais, entre elas pela IAAF adotou como base normativa o princípio da responsabilidade estrita objetiva, ou "strict liability principle" proveniente da "common law", onde o atleta é responsável por tudo o que se encontrar em seu organismo, não importando a forma como se deu a entrada da droga. Assim sendo, sua responsabilidade independe de culpa, negiligência, imprudência, imperícia ou dolo. .,10,12,13 $^{2}$

Ao analisar os casos punidos pelo STJD do atletismo entre os anos de 2003 a 2006 percebesse que tal princípio é utilizado, muito embora em discordância com o princípio da presunção de inocência constantes na Constituição da República
Federativa do Brasil de 1988 (CRFB) 88) e na Declaração Universal dos Direitos Humanos de 1948 da qual o Brasil também é signatário.

METODOLOGIA

Esta Pesquisa assumiu um caráter descritivo do tipo documental onde foram analisados 18 processos pelo uso de substância proibida, entre os anos de 2003 a 2006 junto a Justiça Desportiva do Atletismo, de atletas do sexo masculino e feminino que tiveram participação constante em eventos nacionais e internacionais. $\mathbf{O}$ instrumento utilizado para obtenção dos dados foi a técnica da observação dos documentos arquivados junto a Confederação Brasileira de Atletismo [CBAt].

Segundo as normas adotadas pela Confederação de Atletismo que segue as normas adotadas internacionalmente pela WADA são consideradas violações das normas antidopagem: a presença de uma substância proibida, dos seus metabólitos ou marcadores; a utilização ou tentativa de uma substância proibida ou de um método proibido; a recusa ou falta sem justificação válida ao exame de controle, após notificação; a disponibilidade do praticante nos controles fora de competição; a falsificação ou tentativa de falsificação de qualquer componente integrante do controle de dopagem; a posse de substâncias e métodos proibidos; o tráfico de qualquer substância ou método proibido e a administração ou tentativa de administração de uma substância proibida ou método proibido a qualquer praticante. .,6,8,9,10,14,15 A punição aplicada pelo STJD do Atletismo também segue as normas internacionais e correspondem a no mínimo 2 anos de suspensão e banimento do esporte em caso de reincidência. ${ }^{8}$

\section{RESULTADOS}

A tabela 1 apresenta o resultado dos 18 processos analisados. Pela análise percebesse que somente 03 dos 18 processos analisados conseguiram uma sentença favorável ao atleta. Um por que não fora realizado o teste de dopagem, mas tão somente encontrada substância proibida em seu alojamento. De acordo com a decisão proferida pelo STJD não foram seguidos corretamente os procedimentos internacionais e finalmente, o último em que todas as provas dos autos levaram a crer que a atleta não concorreu para que a substância fosse encontrada em seu organismo. Mas, urge ponderar que mesmo tendo sido estes 2 últimos absolvidos pela justiça desportiva brasileira, receberam punição, sendo certo que o primeiro realizou acordo junto a confederação e ficou 2 anos inelegível a fim de não ser encaminhado ao corte arbitral do esporte ela IAAF e a última recebeu punição junto a este tribunal internacional e não pode competir por dois anos, mesmo tendo sido flagrada pelo exame antidoping em uma competição nacional.

Em todos os demais processos prevaleceu o princípio da responsabilidade objetiva.

\section{DISCUSSÃO}

Assim sendo, torna-se mister fazer uma diferenciação entre estes dois tipos de responsabilidade: a subjetiva e a objetiva, proveniente da common law.

0 princípio da responsabilidade subjetiva está baseado na culpa do agente, ou seja, o agente só será responsabilizado se agiu com dolo ou com culpa, sem estes elementos 
não há o que se falar em responsabilidade. Ao passo que para a responsabilidade objetiva não existe a indagação de culpa, ou seja, o agente responderá independente desta, sendo certo que esta decorre tão somente quando existe previsão legal. ${ }^{3,9,10,11,16}$

Ocorre que as normas de controle antidoping adotadas pela IAAF (International Association of Athletics Federations], bem como pela CBAt (Confederação Brasileira de Atletismo] seguem a risca as orientações da WADA (World AntiDoping Agency) que prevê a responsabilidade objetiva do atleta flagrado com substância proibida. No entanto, cumpre ponderar que tal regra afronta indubitavelmente, não só nossa Constituição Federal de 1988, mas também a Declaração Universal dos Direitos Humanos datada de 10/12/1948, tendo em vista que não respeita o princípio da presunção de inocência que deve ser aplicado a todo e qualquer indivíduo que esteja sendo acusado de ato ilícito.

Segundo a Declaração Universal dos direitos humanos, em seu artigo 11-1, Toda a pessoa acusada de um ato delituoso presume-se inocente até que a sua culpabilidade fique legalmente provada no decurso de um processo público em que todas as garantias necessárias de defesa lhe sejam asseguradas. $7,12,13,15$

Para a Constituição da República Federativa do Brasil /1988, art. 5, Inciso LVII, também vige o princípio de presunção de inocência do acusado: "Ninguém será considerado culpado até o transito em julgado de sentença condenatória". 4

Desta forma, percebesse que o princípio da responsabilidade objetiva vigente nas normas antidoping fere não só nossa constituição, mas também a Declaração Universal dos Direitos Humanos, pois atribui responsabilidade a um agente, independentemente de que se comprove que o mesmo tenha agido com dolo ou culpa para com o caso concreto. Como pode um atleta sofrer sanções tão graves, que podem até mesmo vir a colocar um fim em sua carreira, mesmo comprovando que não deu causa para que tal fato ocorresse? Como dizer que lhe fora conferido o direito a ampla defesa e ao contraditório se ao final do processo o mesmo responderá mesmo comprovando que não agiu com dolo ou culpa? No mínimo inconstitucional tal penalidade.

Após a verificação dos 18 processos julgados perante a Justiça Desportiva do Atletismo entre os anos de 2003 e 2006 é nítido que a regra da responsabilidade objetiva confronta com nossos princípios constitucionais e com a declaração universal dos direitos humanos, levando atletas a responderem por ato ilícito para o qual não restou devidamente comprovada sua culpa. 0 fato de haver a possibilidade de oferecer defesa perante a justiça desportiva não caracteriza que as regras constitucionais do contraditório e da ampla defesa estejam sendo cumpridas, pois apesar de haver provas constantes nos autos de que a ingesta de substância proibida se deu por motivos alheios a vontade do atleta este responderá, pois é o único responsável por tudo o que é encontrado em seus fluídos corporais.

Desta forma, percebesse que tal ordenamento encontrasse em dissonância tanto com o diploma constitucional quanto com a Declaração Universal dos Direitos Humanos, afinal não pode uma regra comum ser superior aos institutos supra citados.

\begin{tabular}{ccc}
\hline Processos & $\begin{array}{c}\text { Sentença } \\
\text { [STJD] }\end{array}$ & $\begin{array}{c}\text { Intervenção } \\
\text { da IAAF }\end{array}$ \\
\hline 03 & Absolvição & 02 \\
15 & Suspensão \\
\hline \multicolumn{3}{c}{ TABELA1 } \\
Processos julgados por doping perante \\
o STJD do Atletismo - 2003/2006.
\end{tabular}

Por fim, urge ponderar que não se está aqui fazendo uma apologia ao uso de substâncias dopantes, muitos menos, se tentando isentar de responsabilidade atletas que comprovadamente tenham se valido desses recursos para obter vantagens sobre os demais atletas, mas tão somente levar a atenção dos que militam na área desportiva ou tão somente tenham prazer em acompanhar um evento desportivo sobre a situação de atletas que tenham sido flagrados pelo exame antidoping, mas que não tenham dado causa ao ilícito.

Afinal espera-se que uma competição seja pautada em ideais de igualdade de condições, onde um atleta somente ganhe quando obtiver de forma leal as condições que o levaram ao pódio.

\section{CORRESPONDÊNCIA}

Renata da Cruz Cunha

Estrada do Rio Morto 197

bloco 07 casa 102 - Vargem Grande

- Rio de Janeiro / RJ - Brasil

Email:

renatacruzcunha@yahoo.com.br

Tel.: 55-021-24283597

55-021- 81902822

55-021-78274548 


\section{REFERÊNCIAS}

1. Alkmim, RMN. (2004) Esporte e Drogas - Atletismo. Rev Running $B R$; 1:3-6.

2. Burns, CN. [2006) Doping in sports. New York: Nova Science Publishers.

3. Cavalieri Filho, S. (2003) Programa de Responsabilidade Civil. São Paulo: Editora Malheiros. Vol 1.

4. CRFB/88 (2007) Constituição da República Federativa do Brasil. São Paulo: Editora Revista dos Tribunais.

5. Giulianotti R. (2004) Human Rights, Globalization and Sentimental Education: The Case of Sport. Sport in Society. 7:355-369.

6. Hoberman JM, Møller V. (2004) Doping and public policy. Odense Portland, OR: University Press of Southern Denmark ; Distribution in the United States and Canada: International Specialized Book Services.

7. Houlihan, B. (2004) Civil Rights, Doping Control and the World Anti-doping Code. Sport in Society. 7:420-437.

8. Machado RAEA. (2007) Curso de Direito Desportivo Sistêmico. São Paulo: Editora Quartier Latin. 1:574.
9. Puga, A. (2004) Dopagem: Procedimentos Especiais e Penalidades. In Código Brasileiro de Justiça Desportiva. Comentários e Legislação. Ministério do Esporte.

10. Puga, A. (2004) Código Mundial Antidoping: Ética e Fair Play no Esporte Olímpico. efdeportes, 10.

11. Silva ML, Katia ER (2003) Superação no Esporte: Limites Individuais ou Sociais? Rev Port Ciênc Desp. 3:69-76.

12. Soek J. (2006a) The Strict Liability Principle and the Human Rights of Athletes in Doping Cases. Cambridge: Cambridge University Press.

13. Soek J. (2006b) The Strict Liability Principle and the Human Rights of the Athlete in Doping Cases. Rotterdam: Thesis Erasmus University Rotterdam.

14. Tavares 0 (2007) Notas Para Uma Análise da Produção em Ciências Sociais Sobre Doping no Esporte. Esporte e Sociedade Revista Digital. 2(4).

15. World Anti-Doping Agency (2002). Annual Report. Montreal: Anthony Philbin Design.

16. Yonamine M, Garcia PR et al. (2004) Non-intentional doping in sports. Sport Med. 34(11):697-704.

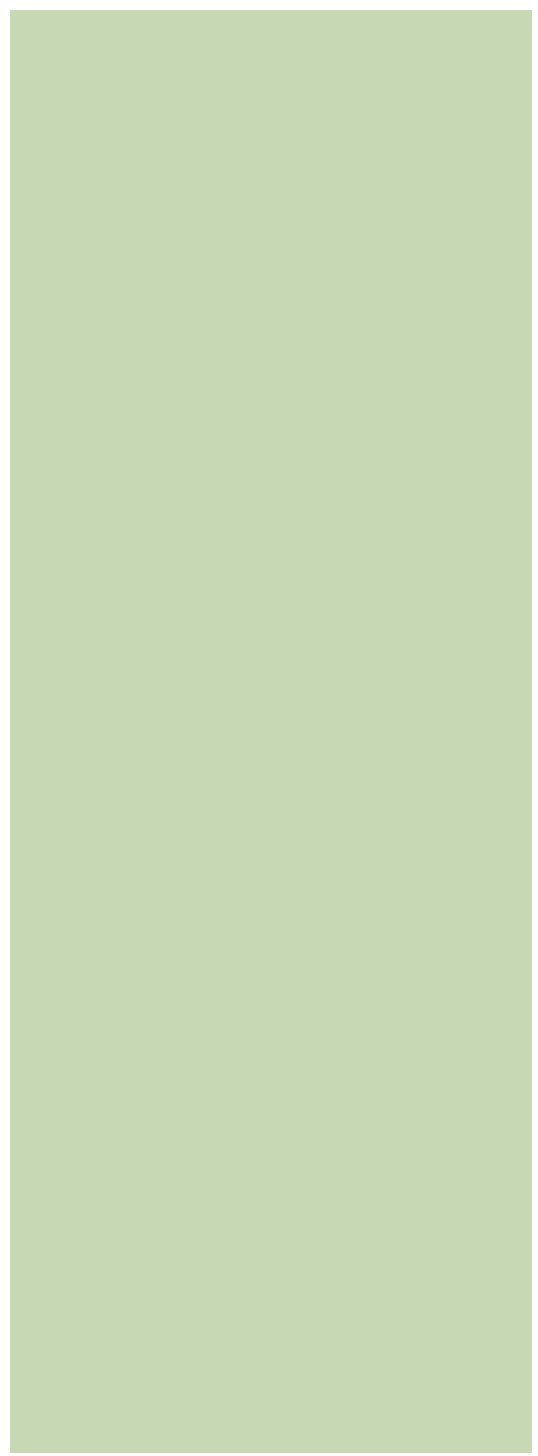

